Article

\title{
Decision Support System for a Low Voltage Renewable Energy System
}

\author{
Iulia Stamatescu *, Nicoleta Arghira *, Ioana Făgărăşan, Grigore Stamatescu, \\ Sergiu Stelian Iliescu and Vasile Calofir
}

Department of Industrial Automation and Informatics, Faculty of Automatic Control and Computers, University "Politehnica" of Bucharest, 313 Splaiul Independentei, 06004 Bucharest, Romania; ioana@shiva.pub.ro (I.F.); grigore.stamatescu@upb.ro (G.S.); iliescu@shiva.pub.ro (S.S.I.); vasile@shiva.pub.ro (V.C.)

* Correspondence: iulia.stamatescu@aii.pub.ro (I.S.); nicoleta.arghira@aii.pub.ro (N.A.); Tel.: +40-21-402-9147 (I.S.)

Academic Editor: Wenxin Liu

Received: 6 November 2016; Accepted: 9 January 2017; Published: 18 January 2017

\begin{abstract}
This paper presents the development of a decision support system (DSS) for a low-voltage grid with renewable energy sources (photovoltaic panels and wind turbine) which aims at achieving energy balance in a pilot microgrid with less energy consumed from the network. The DSS is based on a procedural decision algorithm that is applied on a pilot microgrid, with energy produced from renewable energy sources, but it can be easily generalized for any microgrid. To underline the benefits of the developed DSS two case scenarios (a household and an office building with different energy consumptions) were analyzed. The results and throw added value of the paper is the description of an implemented microgrid, the development and testing of the decision support system on real measured data. Experimental results have demonstrated the validity of the approach in rule-based decision switching.
\end{abstract}

Keywords: power systems; microgrid; decision support system; distributed energy resources; renewable energy sources; low voltage renewable energy system

\section{Introduction}

A microgrid is defined as "a group of interconnected loads and distributed energy resources (DER) with clearly defined electrical boundaries that act as a single controllable entity with respect to the grid and it can connect and disconnect from the grid to enable it to operate in both grid-connected or island mode" [1]. The benefits of this concept lie in the advanced functions that are available, such as setting the operation mode: on-grid or islanding when energy cannot be supplied from the national grid (during peak times of the day).

Microgrids could be described as upgraded electrical networks which possess two-way digital communication between the supplier and consumer, intelligent metering, and monitoring systems [2]. Microgrid technology incorporates traditional elements, as well as new generation elements: a set of control systems and grid management, sensors, communications, and information systems. It combines software and hardware designed to significantly improve the way the current energy system is operated, while providing the possibility of further modernization.

The benefits of a microgrid can be widely acknowledged. Microgrids can manage direct communication and interaction among energy distribution companies, households, or consumers. The implementation of the microgrid opens several possibilities to consumers to directly control and manage their individual consumption patterns [3]. Among the undisputed benefits, a slight disadvantage lies in the variability of electricity prices, which directly impacts energy usage prediction [4]. 
Microgrids will be the foundation stone of future decentralized power systems. This will open the window of opportunity for the usage of on-shore and off-shore renewable energy and electric vehicles, while maintaining availability for conventional power generation and power system adequacy [5]. Using the microgrid technology the consumers have access to real-time information about their energy consumption, having the possibility to make smart choices about the energy usage. Thus, consumers will be able to reduce consumption during times of peak consumption, adjusting the amount taken from the grid [6].

The agenda of the European Union for 2020 comes with a clear message regarding the energy field. The future energy infrastructure should develop the efficient and sustainable use of natural resources. The existing grid must be upgraded, otherwise the generation of renewable energy will be put on hold, the internal energy market will develop slower, and energy efficiency and savings will be missed [7].

The distributed power generation in the low voltage electrical networks (supplied at 230/400 V) has a very important role in the international research due to its effects and its technical implementation [8]. More precisely, the local power generation losses of distributed power can be compensated, but an excess of power can generate overloads of the electric line, providing instability of the network [9]. Hence, the rational management of the electrical energy must be ensured to maintain the balance of power/energy on each line of the network (generated power equal to consumed power) [10]. The differences from this ideal case led to over- and under-production of energy and the stability of the distributed power system will be perturbed [11,12].

Additionally, energy flow optimization should be tackled. In the context of RES, the optimization function should consider uncertainties. Another important challenge is the minimization of the energy costs, [13]. Solutions for centralized control and optimization for integrated energy systems were developed to minimize the energy waste in the generation process as well, [14]. Information systems that support themselves on artificial intelligence techniques and consider knowledge and reasoning (rules) can be a solution for power flow computation, optimization, and planning. Bayesian networks, fuzzy systems, decision trees, and decision tables were used for power system control and optimization in the later literature $[15,16]$.

European concern for distributed generation from renewable energy systems (DG-RES) were materialized by setting up a giant cluster of projects called the Integration of Renewable Energy Sources and Distributed Generation into the European Electricity Grid-Integration of Renewable Energy Sources and Distributed Generation into the European Electricity Grid (IRED) cluster [17]. The consortium highlighted the need of an energy management system at a macro and micro level considering that the existing control strategies were not always giving the optimal results.

In this context, the paper presents the implementation of a decision support system for a low-voltage grid with renewable energy sources (photovoltaic panels and wind turbine). The goal of the decision-based control system is to achieve energy balance in the microgrid with less energy consumed from the grid.

\section{Decision Support Solutions for Power Systems}

Decision support systems (DSS) are information systems that integrate dedicated informatics objects for decision assistance and general instruments as a constituent part of the global system [14]. In power systems (PS), DSSs are more and more studied in the last years when variable energy renewable sources generate in power grids. The main goal of the studied decision support systems is to maintain the load-generation balance always (to assure the adequacy of the power system). The solutions concern:
A. PS planning $[18,19]$
B. PS operation $[20,21]$

Authors in [19] propose a methodology for jointly tackling the problem of determining the number, location, type, and size of distributed generators (DGs), while also considering the availability 
of the (renewable) sources that DGs harvest. This approach is applied in the planning phase of the power system when the meta-heuristic algorithm (e.g., particle swarm optimization) result sets the amount of renewable energy that can be connected to a specific electrical line/bus.

Power system planning is very challenging and a framework for a decision-making aid was proposed in [20]. A complex consumption model was developed considering heating, electricity, and transportation as well as cost and environmental aspects. The paper computes distinctly the energy consumption and generation, but the decision is left for the system operators.

The DSS described in [21] is part of B type DSSs and it describes a simulation-based decision support tool that considers prediction of the performance of photovoltaic panel (PV), wind, and battery technologies to achieve load-generation balance. The matching of supply options to demand profiles is quantitative measured through an inequality coefficient. Still, the computation formula is not clear, nor is the used algorithm, and the results of the case study are not provided.

A complex smart decision support system for the smart city of Florence in Italy that handles different areas (transport and mobility, commercial, environment, energy) was proposed in [22]. The decision-making process was based on hierarchical decision trees and each node has three options: positive, negative, and uncertain. The outcome of the decision tree is based on a bottom-up strategy [23], but in this paper the main importance is given to user's option. An adapted smart DSS architecture for a microgrid is proposed in Figure 1.

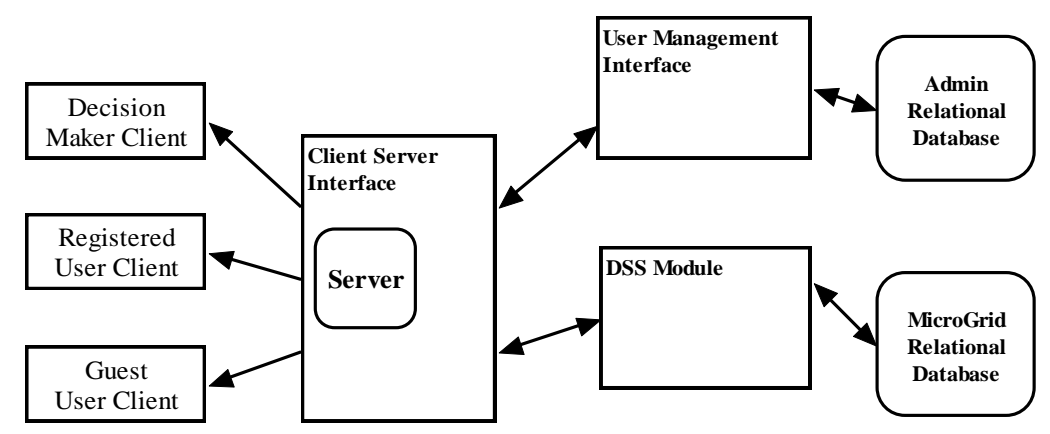

Figure 1. Smart DSS architecture for a microgrid, adapted from [22].

A decision tree approach for controlled islanding of a microgrid is presented in [24], as are decision rules concerning the situations when incidents occur with continuous monitoring of the system parameters (voltage, frequency, harmonics, current, etc.). This DSS based on an event classification model (different types of faults) can be used for initiation of controlled islanding of the microgrid.

The literature survey shows different strategies used for decision support systems, but the outcome of these studies does not offer specific power generation-consumption balance solutions. The need for proposed scenarios involving different types of distributed generation in microgrids for the users to be adopted is called for.

\section{The Microgrid Hardware Architecture}

The proposed microgrid (Figure 2) is implemented at the CIST Multidisciplinary Scientific and Technologic Research Institute (ICSTM) of "Valahia" University of Targoviste (UVT) [25]. The research institute is spread over an area of $7250 \mathrm{~m}^{2}$ and has $2240 \mathrm{~m}^{2}$ built area, which includes 35 research laboratories, five technical laboratories, six functional annexes, seven administrative spaces, and four dissemination spaces. The studied microgrid is composed of three subsystems:

- Subsystem 1: 10 photovoltaic panels (10 PVs) with a maximum power of $\mathrm{P}_{10 \mathrm{PV} \max }=50 \mathrm{~W}$.

- Subsystem 2: a photovoltaic panel (1 PVBat) with a maximum power of $\mathrm{P}_{\mathrm{PVBat} \max }=220 \mathrm{~W}$ and a bank of batteries.

- Subsystem 3: a wind system (EOL400) with a maximum power of $\mathrm{P}_{\mathrm{EOL} \max }=400 \mathrm{~W}$. 


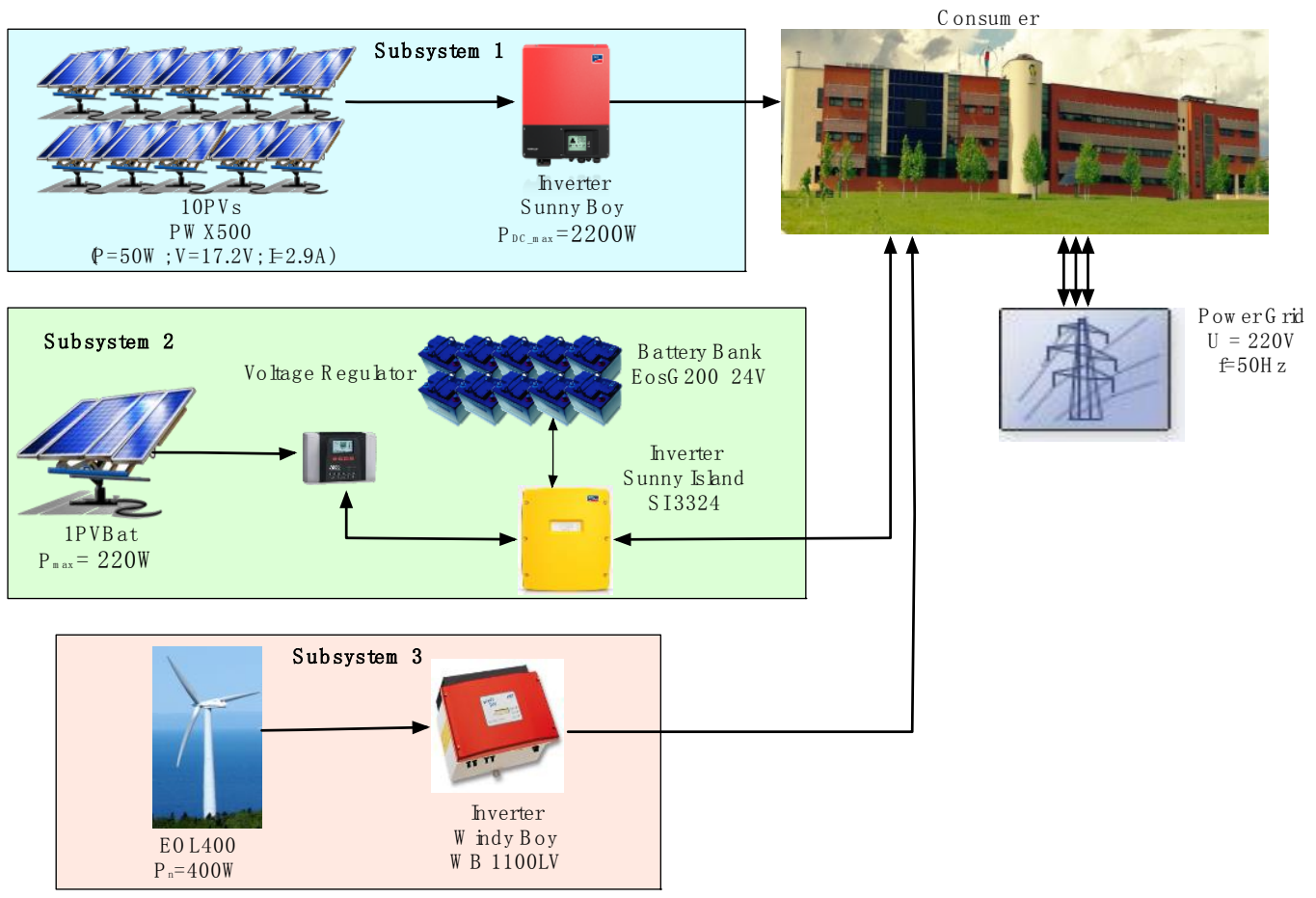

Figure 2. The developed hardware infrastructure-pilot microgrid.

Subsystem 1 (Figure 3) is composed of: 10 photovoltaic panels (10 PVs) (Figure 4a) and an inverter (Figure $4 \mathrm{~b}$ ). The $10 \mathrm{PVs}$ were oriented east-west, with an area of southern exposure and their inclination is about 30 degrees. The PVs are PWX500 type (power $=50 \mathrm{~W}$, voltage $=17.2 \mathrm{~V}$ and current intensity $=2.9 \mathrm{~A}$ ) and they were produced by PhotoWatt International Co (Bourgoin-Jallieu, France) [26]. The $10 \mathrm{PVs}$ photovoltaic system mounted on the terrace is connected to a Sunny Boy SB2100TL inverter (maximum power $=2200 \mathrm{~W}$, maximum voltage $=600 \mathrm{~V}$, minimum voltage $=125 \mathrm{~V}$ ) from SMA (Niestetal, Germany) which is connected to the local power network.

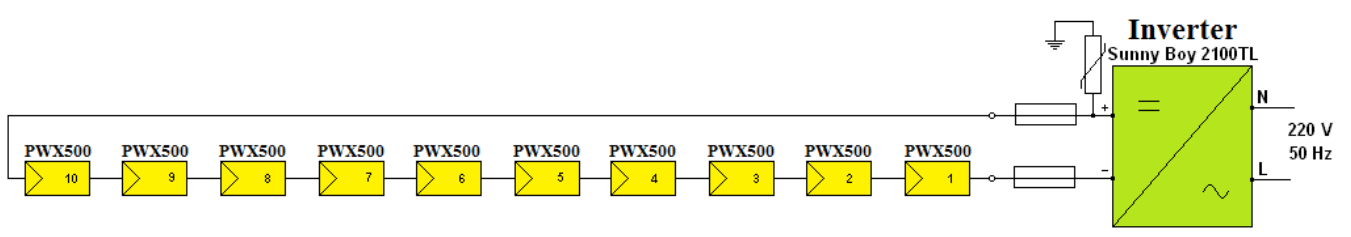

Figure 3. Block diagram of the 10 photovoltaic panels connected to the local power network.

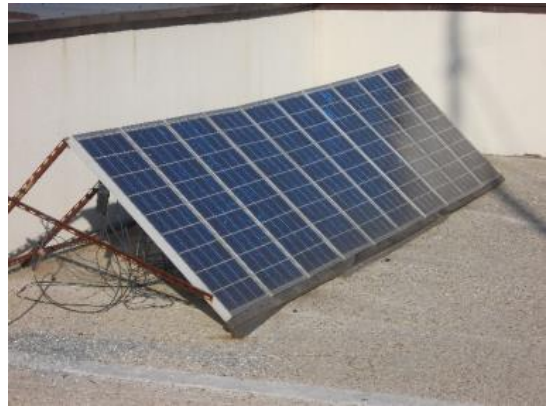

(a)

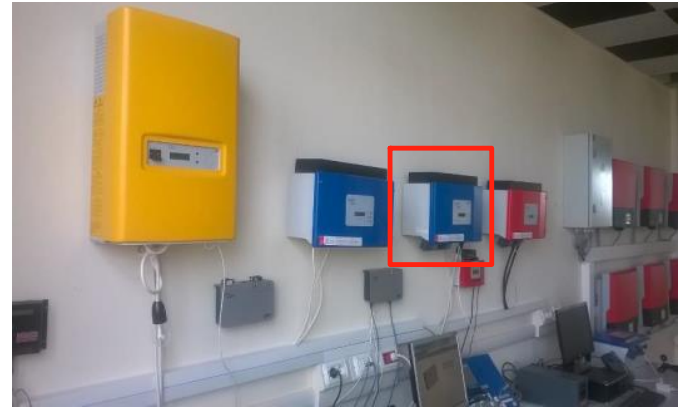

(b)

Figure 4. The components of the subsystem 1: (a) 10 photovoltaic panels; and (b) the Sunny Boy SB2100TL inverter. 
Subsystem 2 (Figure 5) is composed of a photovoltaic panel (1 PVBat) (Figure 6a), an inverter (Figure 6b), a voltage regulator (Figure 6c) and a battery bank (Figure $6 \mathrm{c}$ ). The photovoltaic panel was oriented east-west, with an area of southern exposure and an inclination of about 30 degrees. The photovoltaic system used in this application are produced by Sunshine Solar Technology Co (Huaxi Industrial Zone, Wuxi, China) and the technical characteristics of the ST220 type PV are as follow: maximum power $=220 \mathrm{~W}$, maximum current intensity $=36.6 \mathrm{~V}$, maximum power point voltage $=30 \mathrm{~V}$, maximum power point current intensity $=7.345 \mathrm{~A}$ [27]. The 1 PVBat is mounted on the terrace and it is connected to a bank of batteries via a $24 \mathrm{~V}$ voltage regulator (Steca Tarom 245-24V-45A type (Memmingen, Germany)). Subsystem 2 is connected to the local power network with a Sunny Island SI3324 inverter (maximum voltage $=32 \mathrm{~V}$, minimum voltage $=21 \mathrm{~V}$ ) from SMA (Niestetal, Germany). The battery bank consists of 12 lead-gel batteries (type Polymer Gel Battery Standby EosG200 2V200Ah from Narada (Hangzhou, China)), with the individual voltage of $2 \mathrm{~V}$, connected in series. Following this configuration, the bank's terminals have $24 \mathrm{~V}$.

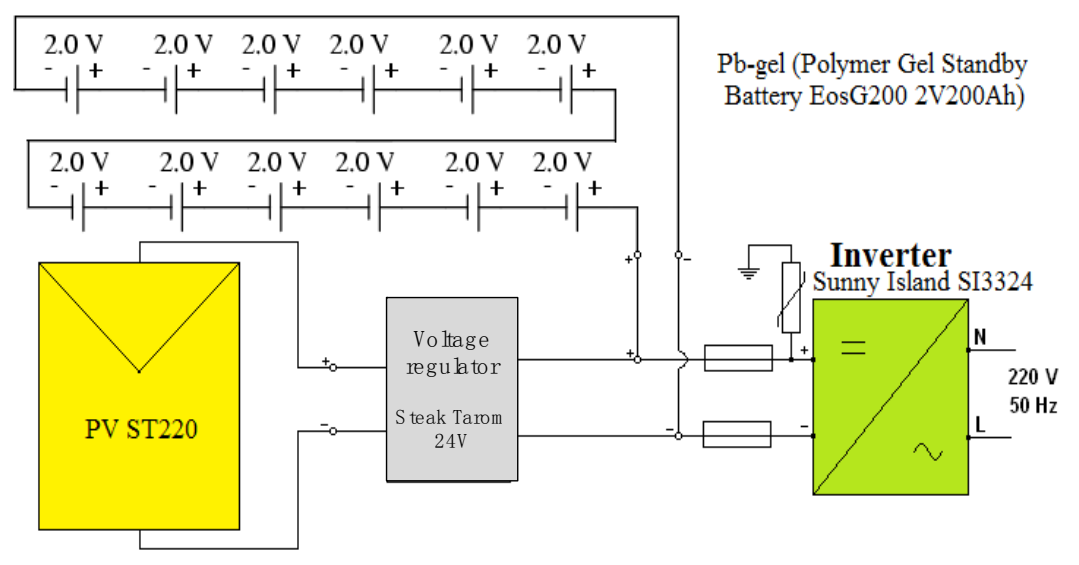

Figure 5. Block diagram of Subsystem 2 connected to the grid.

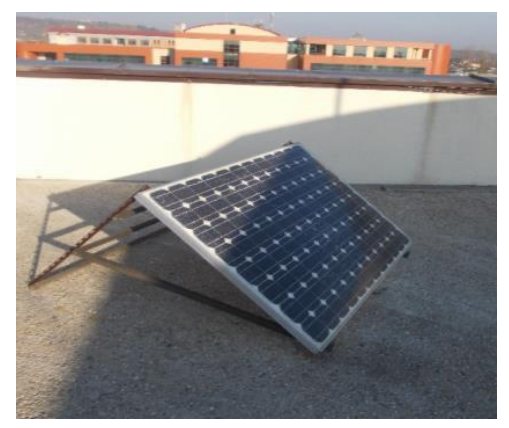

(a)

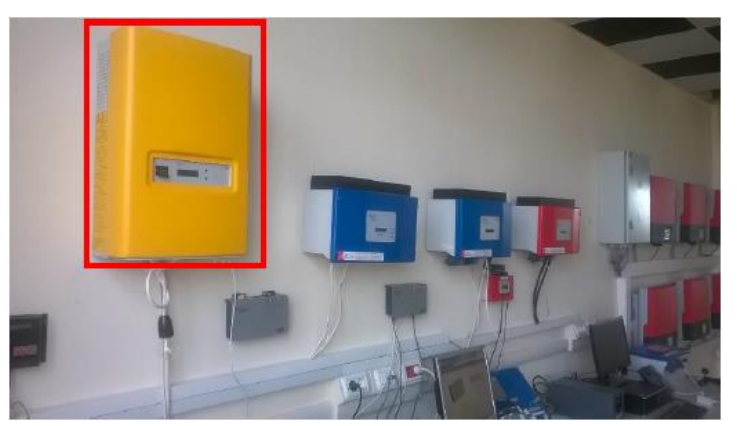

(b)

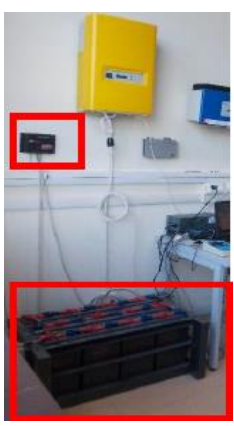

(c)

Figure 6. The components of the subsystem 2: (a) a photovoltaic panel; (b) the Sunny Island SI3324 inverter from SMA; and (c) the battery's bank and the voltage regulator.

Subsystem 3 (Figure 7) is composed of one wind system (Figure 8a) and one inverter (Figure $8 \mathrm{~b}$ ). The wind system (EOL400) is situated about $6 \mathrm{~m}$ above the terrace and it has the following characteristics:

- $\quad$ Rated power $=400 \mathrm{~W}$

- $\quad$ Starting wind speed $=5 \mathrm{~m} / \mathrm{s}$

- Maximum wind speed $=50 \mathrm{~m} / \mathrm{s}$

- Output voltage 20-60 V DC 


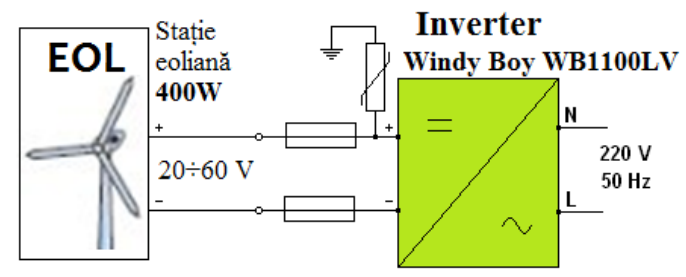

Figure 7. Block diagram of Subsystem 3 connected to the grid.

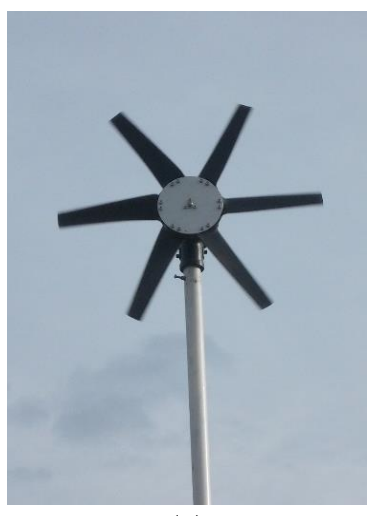

(a)

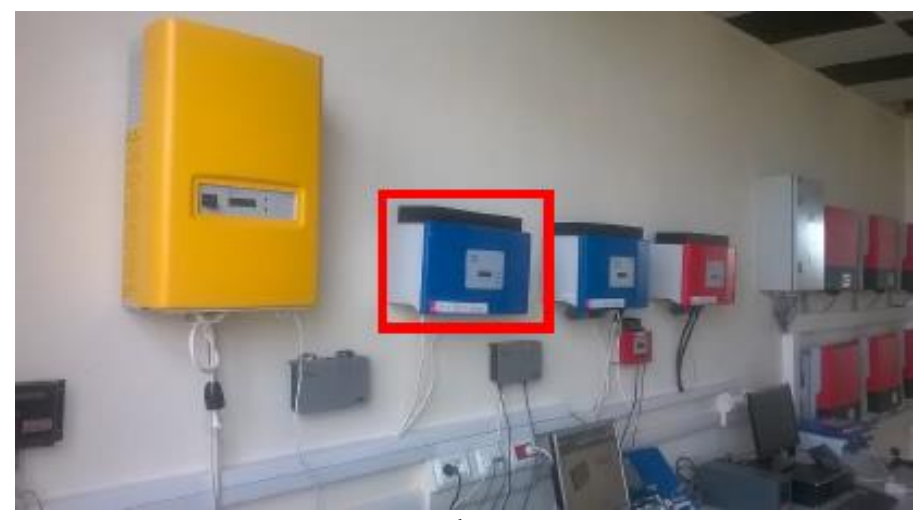

(b)

Figure 8. The components of Subsystem 3: (a) the wind system; and (b) the Windy Boy WB1100LV inverter.

The used inverter in this system is a Windy Boy WB1100LV inverter from SMA (Niestetal, Germany) with the following features: maximum power $=200 \mathrm{~W}$, maximum voltage $=60 \mathrm{~V}$, minimum voltage $=21.3 \mathrm{~V}$. The windy Boy inverter is connected to the local power network.

\section{The Developed Microgrid Controller Software}

The microgrid controller software is used to manage the electrical energy in a low-voltage local grid, connected to the national grid. A block diagram of the microgrid controller software is presented below (Figure 9). The software has four major functions:

- The monitoring function/module

- The diagnosis function/module

- The prediction function/module

- The decision support system module

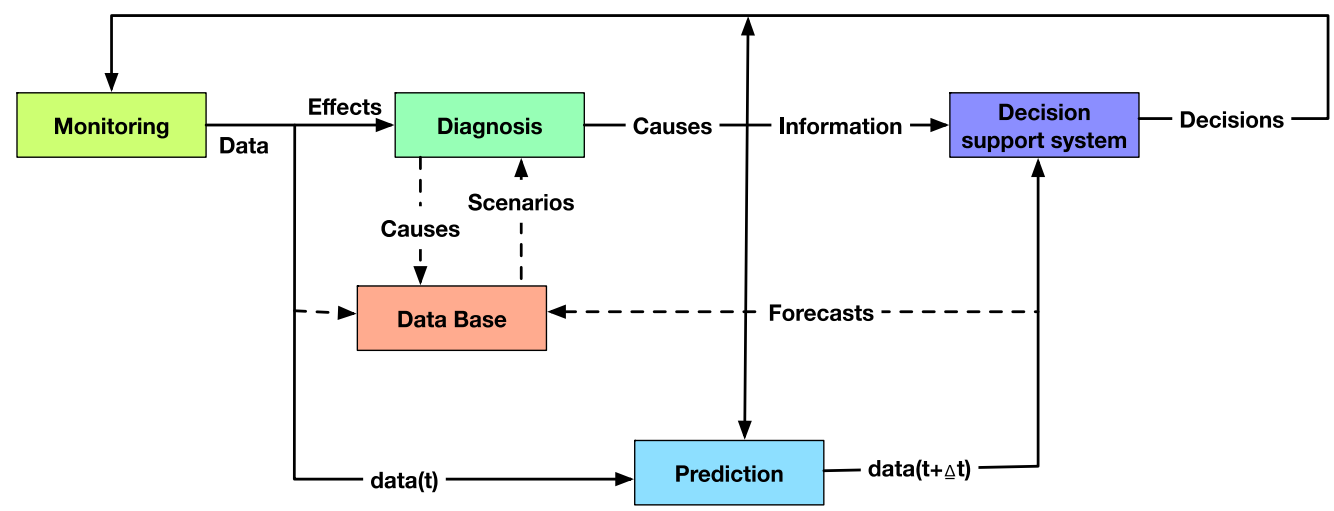

Figure 9. Block diagram of the microgrid software. 
The monitoring function gathers data regarding significant parameters that characterize the energy production and consumption (current, voltage, energy, etc.) and the environment factors (wind speed, irradiance, etc.). The generation parameters can be achieved either by specific sensors or directly from the inverters through the Sunny WebBox device. The monitored data is processed to find the daily energy profile [28].

The diagnosis function is used to evaluate the state of the network, the state of each component, and to identify the causes of damage or an alarm in the network. Fault diagnosis is used to determine the type, size, and location of the fault and the time of its occurrence, based on the analytics observed or heuristic symptoms [29]. The design of the diagnosis function was carried out using methods based on the signal model such as "Fault detection with trend checking and fixed threshold", as well as statistical tests for detecting changes ("Wald Tests").

The method "Fault detection with trend checking and fixed threshold" (Figure 10) is based on calculating the first-order derivative of the signal and monitoring its evolution. If the thresholds are fixed properly this method can detect a fault faster than other methods:

$$
\dot{\mathrm{Y}}=\frac{\mathrm{dY}(\mathrm{t})}{\mathrm{dt}} ; \quad \dot{\mathrm{Y}}_{\min }<\dot{\mathrm{Y}}(\mathrm{t})<\dot{\mathrm{Y}}_{\max }
$$

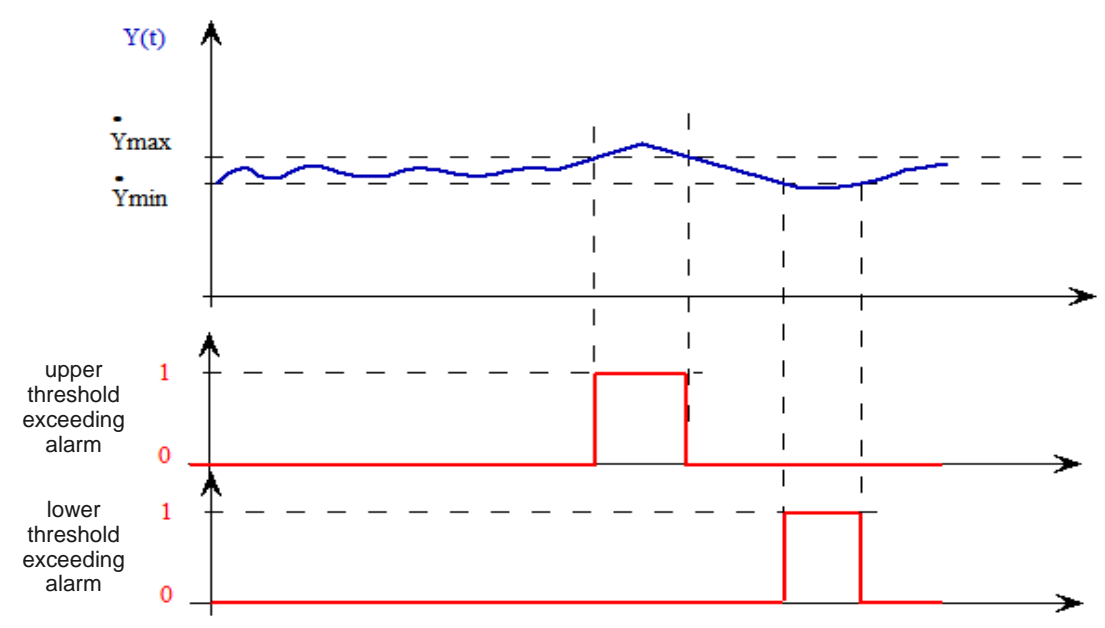

Figure 10. The fault detection method with trend checking and fixed threshold.

The prediction function aims to achieve short and medium-term forecasts of electricity generation from renewable sources in the developed microgrid, as well as the prediction of energy consumption for the used equipment (e.g., lighting, ventilation and heating system, computers, etc.).

Power generation prediction can be achieved using artificial intelligence algorithms. The implementation with an adaptive neuro-fuzzy inference system for RES production prediction was described in [2]. The training set of the test consists of objects with the following attributes: time of day (0-23), season (summer, winter, etc.), month of the year (January, February, etc.), solar radiation, wind speed, active power from photovoltaic panels, active power produced by the wind turbine. The authors in [30] are exploring ways of performing accurate forecasts of generating power from renewable energy sources so that independent system operators can, consequently, act.

The prediction, for the energy consumption of each equipment can be done using a knowledge-based expert system. The historical consumption is used to generate knowledge through a decision table classification method. The result of the classification will show if the equipment will consume $(\operatorname{pr}(h)=1)$ or not $(\operatorname{pr}(h)=0)$ at a certain hour. The electricity consumption will be computed considering the following equation:

$$
\mathrm{P}(\mathrm{h})=\operatorname{pr}(\mathrm{h}) \times \overline{\mathrm{P}}
$$


where $\overline{\mathrm{P}}$ is the mean value of positive power from historical consumption.

The decision function is the one that used information/knowledge from the other three modules and computes decisions (regarding the RES to be used or grid connection) as a support for the users [31]. The application and results of this paper consider the decision support system and it will be detailed in the next chapter of this article.

\section{The Decision Support System and Experiment Results}

\subsection{Decision Support System Principle}

Decision support systems (DSS) are primarily concerned with the representation and processing of explicit knowledge. The DSS's knowledge attribute types are three basic categories: descriptive, procedural and reasoning knowledge [32]. Procedural knowledge consists of a set of procedures for handling various tasks. Examples of procedural knowledge include algorithms, strategies, action plans, programs, and methods [33]. Instances of these three types of knowledge (descriptive, procedural and reasoning) can be applied in the generation of new knowledge and has long been recognized in the building of decision support systems [34].

The developed DSS is based on a procedural decision algorithm that is applied on the pilot microgrid, but it can be easily generalized for any microgrid. The developed decision support system module aims at achieving a set of rules that lead to satisfying the electricity consumed in the studied microgrid.

We define the following:

- $\quad \mathrm{P}_{\mathrm{CONS}}$ is the consumed power (e.g., the institute as consumer) in the developed microgrid.

- $\mathrm{P}_{\mathrm{PV}}$ is the power produced by photovoltaic panels.

- $\mathrm{P}_{\mathrm{EOL}}$ is the power produced by the wind turbine.

- $\mathrm{P}_{\mathrm{BAT}}$ is the power stored in batteries.

- $\mathrm{P}_{\mathrm{GRID}}$ is the output power from the public electricity supply.

The condition that should be satisfied at any time by the microgrid electric network is:

$$
\begin{gathered}
\mathrm{P}_{\mathrm{PV}}+\mathrm{P}_{\mathrm{EOL}}+\mathrm{P}_{\mathrm{BAT}}=\mathrm{P}_{\mathrm{GRID}}+\mathrm{P}_{\mathrm{CONS}} \\
\mathrm{P}_{\mathrm{PV}}=\mathrm{P}_{10 \mathrm{PVs}}+\mathrm{P}_{1 \mathrm{PVBat}}
\end{gathered}
$$

where:

- $\quad \mathrm{P}_{10 \text { PVs }}$ represents the power produced by the first subsystem (10 photovoltaic panels (10 PVs) with a maximum power of $\mathrm{P}_{10} \mathrm{PV}$ max $=50 \mathrm{~W}$ ).

- $\quad \mathrm{P}_{1 \text { PVBat }}$ represents the power produced by the second subsystem (a photovoltaic panel (1 PVBat) with a maximum power of $P_{1}$ PVBat max $=220 \mathrm{~W}$ connected to a bank of batteries).

The $\mathrm{P}_{\mathrm{GRID}}$ power is positive when it receives energy from RES generation and it is negative when the consumer is supplied from the national grid.

The geographic region where the microgrid is installed is favorable to produce energy from renewable sources (wind and photovoltaics). For the system protection, the consumer (ICSTM institute) is linked at the national grid all the time. For the given microgrid, a set of specific rules were designed. The rules tackle the possibilities of energy connection of the specific proposed microgrid.

A set of decision rules are listed in the decision table below (Table 1). Rule 1 state that when the consumed power is greater than the power available from the PV, wind, and batteries, then the system should be connected to the public grid. Rule 2 depicts the situation in which the loaded battery is used when the consumption is higher than the microgrid production. Rule 3 states that if the produced power is greater than the consumed power, the battery will be connected for loading. Rule 4 considers 
the photovoltaic generations lower than the consumption and, if the weather conditions are favorable, the wind turbine must be connected. Rule 5 considers the wind turbine generation lower than the load and, if the weather conditions are favorable, the photovoltaic system needs to be connected. The two available renewable power sources (photovoltaic panels and wind) are connected continuously to the microgrid. Rules 4 and 5 present the situation in which the consumer is active and the battery cannot supply energy. These two account for the commonly-occurring scenarios where increased production of wind energy is mutually exclusive with increased production of photovoltaic energy.

Table 1. The DSS decision rules.

\begin{tabular}{ccc}
\hline No. & Condition & Decision \\
\hline Rule 1. & $\mathrm{P}_{\mathrm{CONS}}>\mathrm{P}_{\mathrm{PV}}+\mathrm{P}_{\mathrm{EOL}}+\mathrm{P}_{\mathrm{BAT}}$ & Public Network (Grid) Connection \\
Rule 2. & $\mathrm{P}_{\mathrm{CONS}}>\mathrm{P}_{\mathrm{PV}}+\mathrm{P}_{\mathrm{EOL}}$ & Connection to the battery supply \\
Rule 3. & $\mathrm{P}_{\mathrm{CONS}}<\mathrm{P}_{\mathrm{PV}}+\mathrm{P}_{\mathrm{EOL}}$ & Battery connection for loading \\
Rule 4. & $\mathrm{P}_{\mathrm{CONS}}>\mathrm{P}_{\mathrm{PV}}$ and favorable weather conditions & Wind generator connection \\
Rule 5. & $\mathrm{P}_{\mathrm{CONS}}>\mathrm{P}_{\mathrm{EOL}}$ and favorable irradiance & Photovoltaic panels connection \\
\hline
\end{tabular}

\subsection{DSS Experiment}

The developed DSS based on the above set of rules was implemented in two case studies. The first case study is implemented on the ICSTM microgrid system for the day of 5 May 2016. Since the consumption of the ICSTM institute is far larger than the generated power, another case study is also considered. In this case study, the developed DSS uses the consumption of a residence. This shows the DSS system operating in a simulation case where the generation and load are approximately equal. With the help of the simulation case, different applied rules can be used and observed.

Further, the energy production of each subsystem described in paragraph 3 is shown.

In Figure 11 the monitored production from Subsystem 1 (10 PV panels, max $500 \mathrm{~W})$ is presented. As expected, maximum power is obtained during the time interval $10 \mathrm{~h}-13 \mathrm{~h}$ and energy generation was achieved between 7 a.m. and 7 p.m. since 5 May was a sunny day.

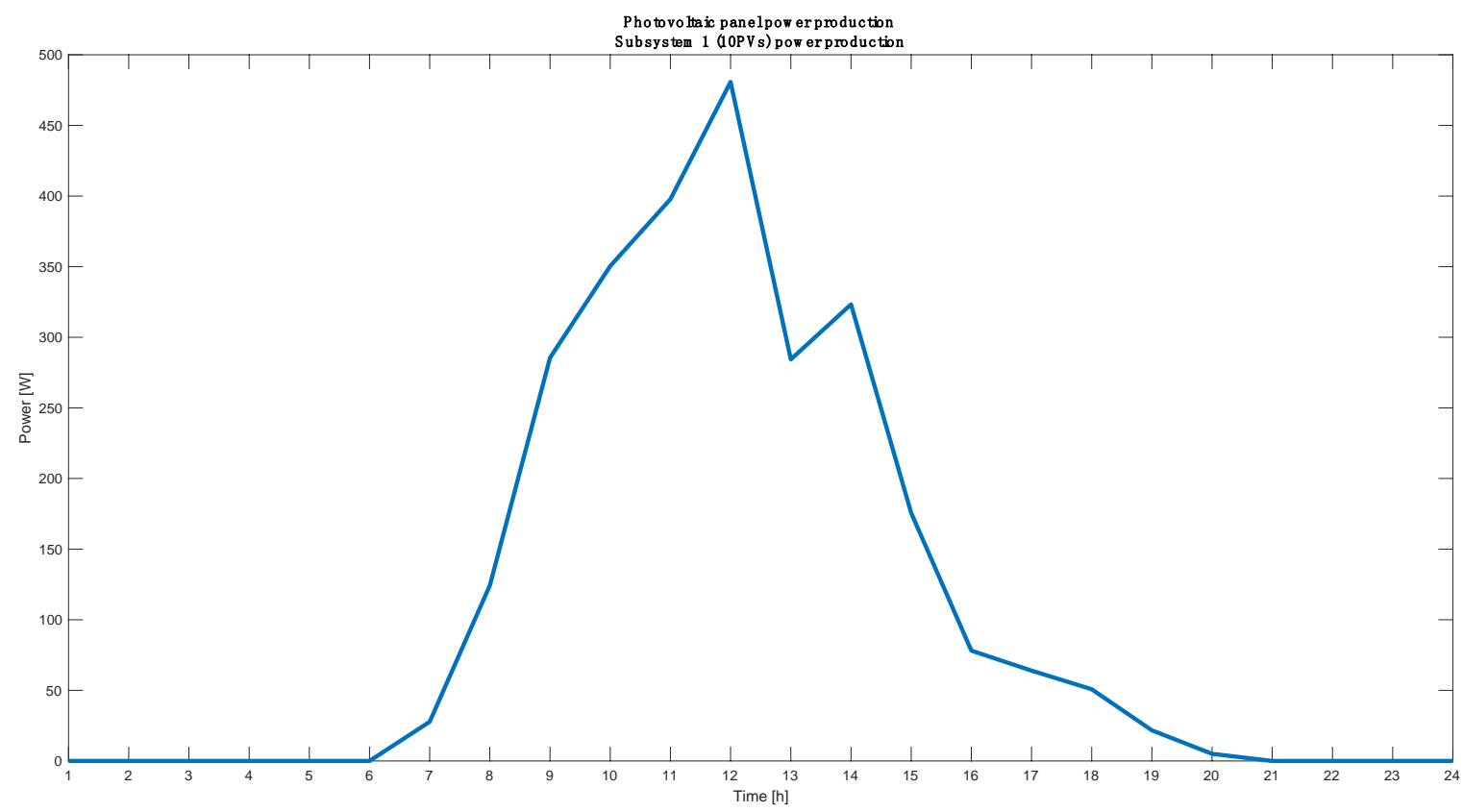

Figure 11. Subsystem 1: 10 PVs generation.

Figure 12 shows the energy production for the PV of Subsystem 2 (max 220 W) on 5 May 2016. Peak production is realized between 10 a.m. and 4 p.m. 


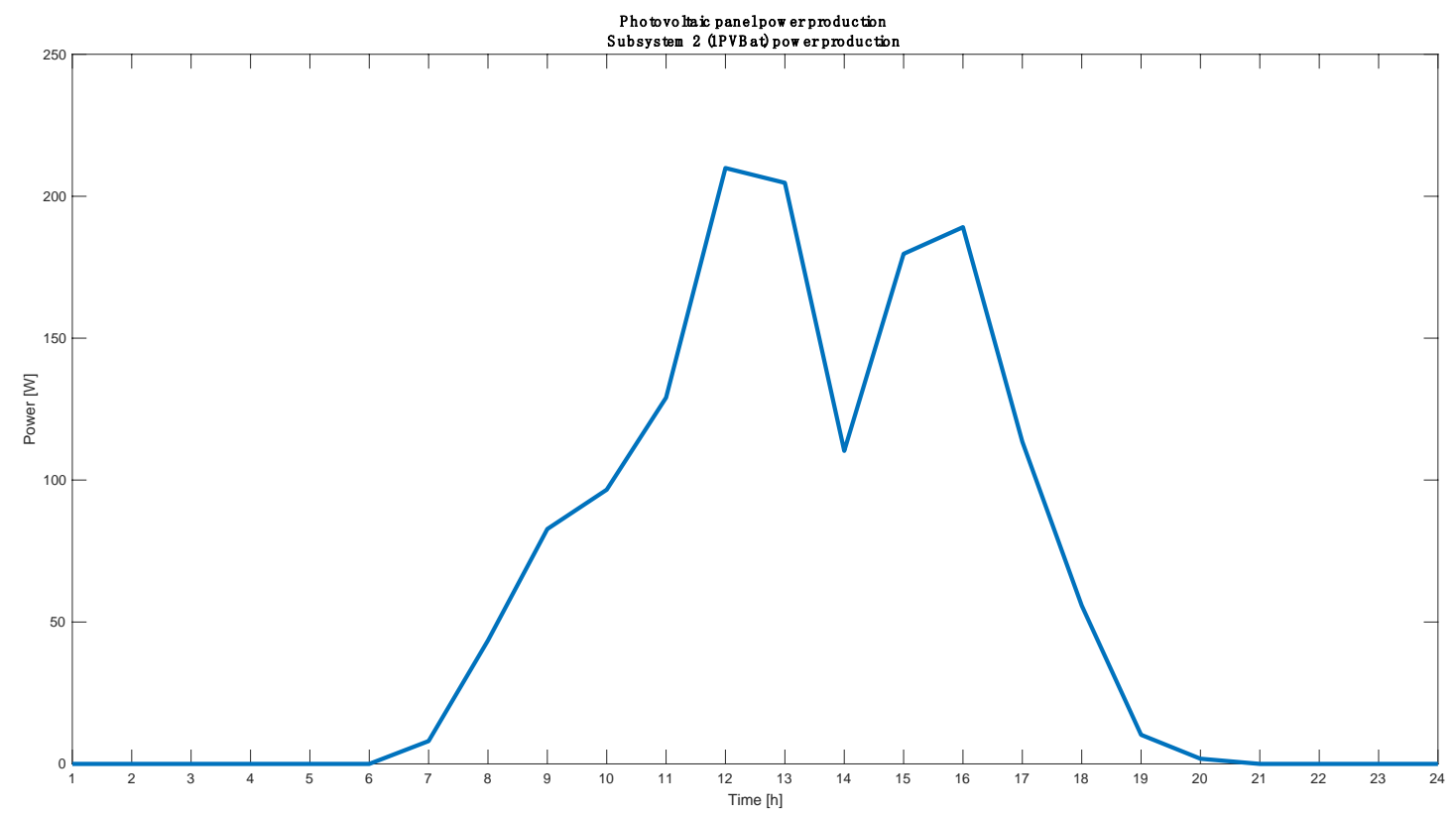

Figure 12. Subsystem 2: 1 PV generation connected to a battery bank.

The wind turbine was not installed in May 2016 but measured data using an online database [35] was used when conducting the experiment. This data is presented in Figure 13.

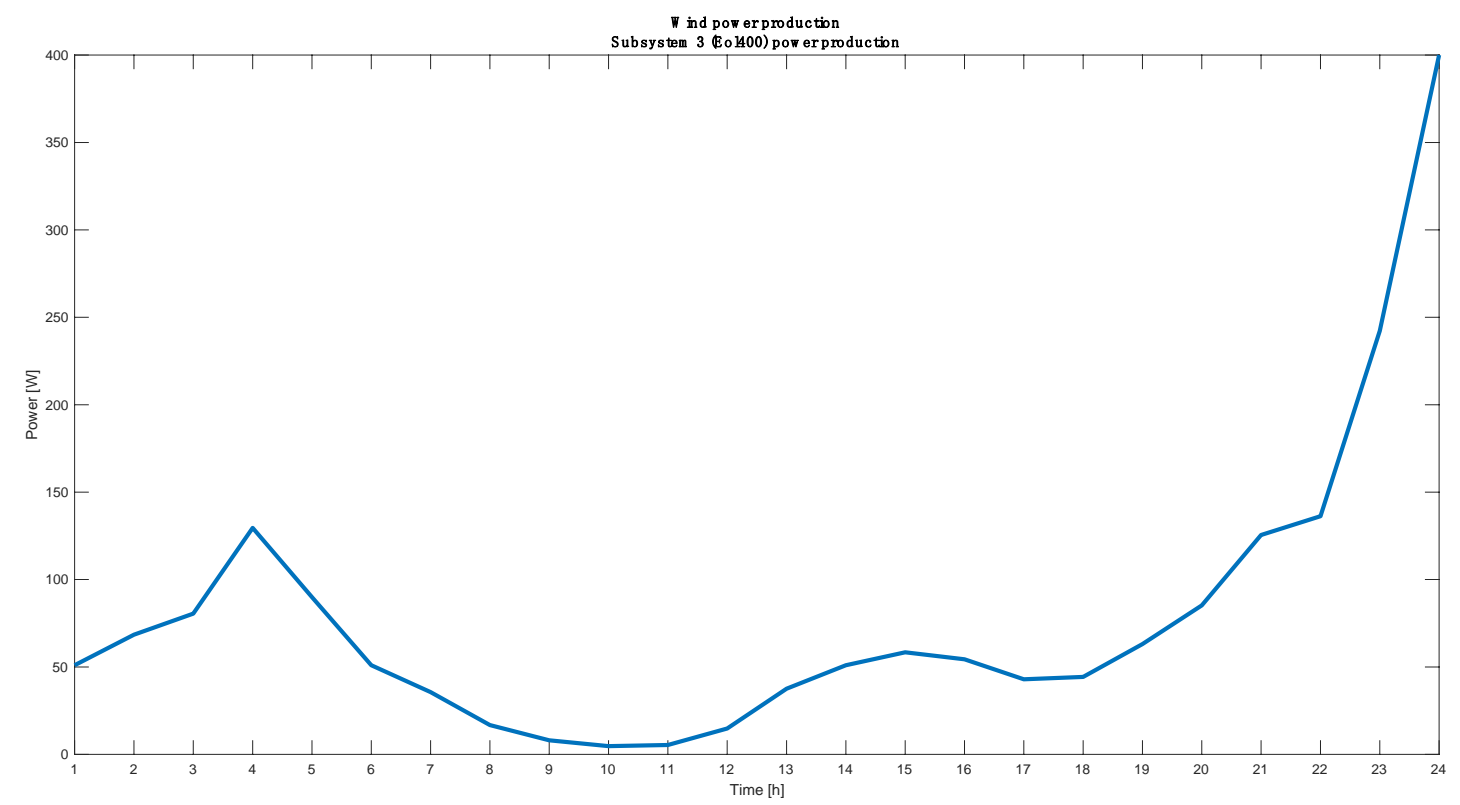

Figure 13. Subsystem 3: wind generation.

The energy consumption was monitored in the building and the DSS rules were implemented overall the microgrid.

\subsection{Results and Discussion}

\subsubsection{Case Study 1-Simulation}

This case study analyzes the power generated by the three subsystems described above (Subsystem 1: 10 PVs generation; Subsystem 2: 1 PV generation connected to a battery bank; and 
Subsystem 3: wind generation) and the consumed power of a residence. The residence consumption is determined by the following appliances: a fridge (180l), a halogen lamp $(0.5 \mathrm{~kW})$ and the power supply from a wood boiler. The DSS output actuates to use the energy supply of one or more of the following: power grid, PV panels, wind turbine, or battery. Both energy production and consumption are represented in Figure 14.

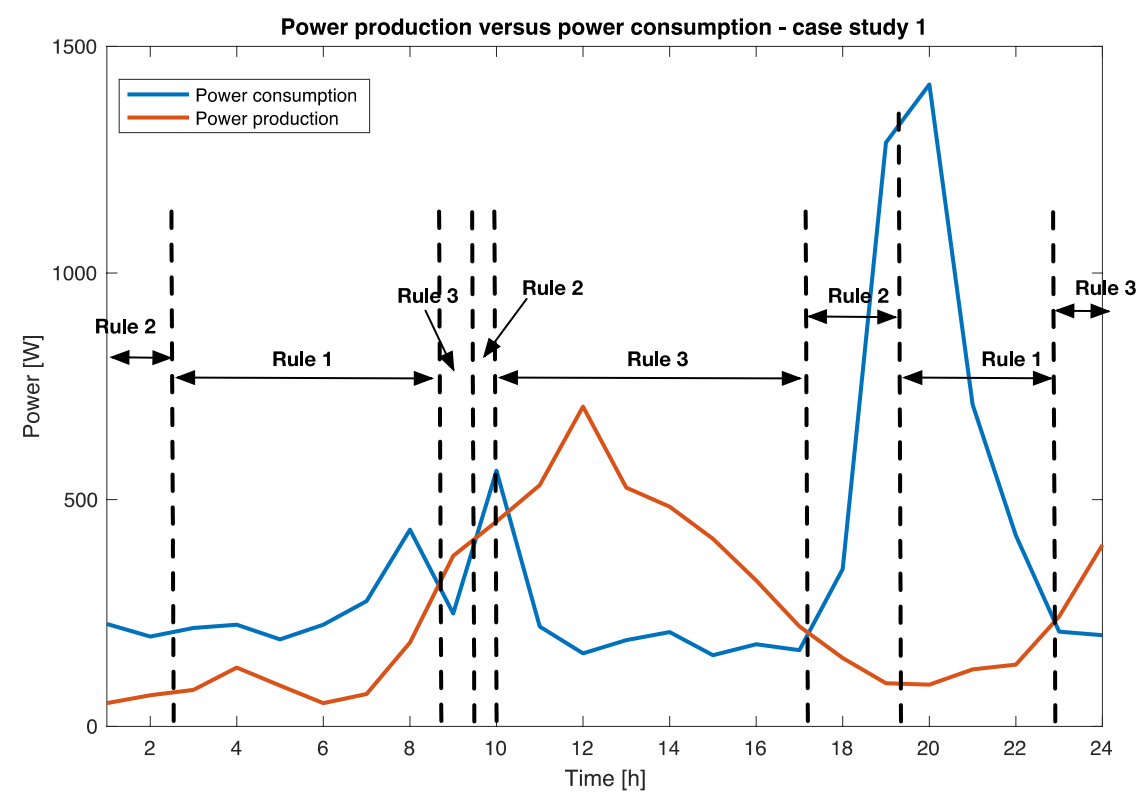

Figure 14. Load-generation curves: case study 1.

An application of the developed decision tree algorithm can be observed in Figure 14 and an hourly detail of the applied rules can be seen in Table 2. The figure shows first that the battery will be used (per its storage capacity) during the day when the consumption is greater than the production (e.g., 1 a.m.-2:15 a.m.). Between 2:15 a.m. and 8:45 a.m. the consumption is greater than the production generated by the wind subsystem, rule 1 will be applied: the command for the connection to the national grid. From 8:45 a.m. to 9:45 a.m. the battery will be connected for loading and the stored energy will be used from 9:45 a.m. to 10:30 a.m. During the day (10:30 a.m. to 17:15 p.m.) the consumer is not active and the bank of batteries will be connected for loading. The accumulated energy will be used first between 17:15 p.m. and 19:30 p.m. when the consumption is greater than the production (wind plus photovoltaic). At night (19:30 p.m. to 23 p.m.) the residence consumption is around $1416 \mathrm{~W}$ so it cannot be covered by the RES generation and the DSS rule involves the connection to the national grid. During the night (23 p.m. to 24 p.m.) the consumer is not active, so it does not use any electricity and the generated power is greater than the consumed power. Though, the battery will be connected for loading and the wind energy production can be stored for later use.

Table 2. Application of DSS decision rules on the simulation case study.

\begin{tabular}{cccc}
\hline Time Interval & Applied Rule & Condition & Action \\
\hline 1 a.m.-2:15 a.m. & Rule 2. & $\mathrm{P}_{\mathrm{CONS}}>\mathrm{P}_{\mathrm{PV}}+\mathrm{P}_{\mathrm{EOL}}$ & Connection to the battery supply \\
2:15 a.m.-8:45 a.m. & Rule 1: & $\mathrm{P}_{\mathrm{CONS}}>\mathrm{P}_{\mathrm{PV}}+\mathrm{P}_{\mathrm{EOL}}+\mathrm{P}_{\mathrm{BAT}}$ & Public Network (Grid) Connection \\
8:45 a.m.-9:45 a.m. & Rule 3. & $\mathrm{P}_{\mathrm{CONS}}<\mathrm{P}_{\mathrm{PV}}+\mathrm{P}_{\mathrm{EOL}}$ & Battery connection for loading \\
9:45 a.m.-10:30 a.m. & Rule 2. & $\mathrm{P}_{\mathrm{CONS}}>\mathrm{P}_{\mathrm{PV}}+\mathrm{P}_{\mathrm{EOL}}$ & Connection to the battery supply \\
10:30 a.m.-17:15 p.m. & Rule 3. & $\mathrm{P}_{\mathrm{CONS}}<\mathrm{P}_{\mathrm{PV}}+\mathrm{P}_{\mathrm{EOL}}$ & Battery connection for loading \\
17:15 p.m.-19:30 p.m. & Rule 2. & $\mathrm{P}_{\mathrm{CONS}}>\mathrm{P}_{\mathrm{PV}}+\mathrm{P}_{\mathrm{EOL}}$ & Connection to the battery supply \\
19:30 p.m.-23 p.m. & Rule 1. & $\mathrm{P}_{\mathrm{CONS}}>\mathrm{P}_{\mathrm{PV}}+\mathrm{P}_{\mathrm{EOL}}+\mathrm{P}_{\mathrm{BAT}}$ & Public Network (Grid) Connection \\
23 p.m.-24 p.m. & Rule 3. & $\mathrm{P}_{\mathrm{CONS}}<\mathrm{P}_{\mathrm{PV}}+\mathrm{P}_{\mathrm{EOL}}$ & Battery connection for loading \\
\hline
\end{tabular}




\subsubsection{Case Study 2}

The DSS output actuate such as to use for energy supply one or more of the following: power grid, PV panels, wind turbine, or battery. Both energy production and consumption of the ICSTM institute are represented in Figure 15.

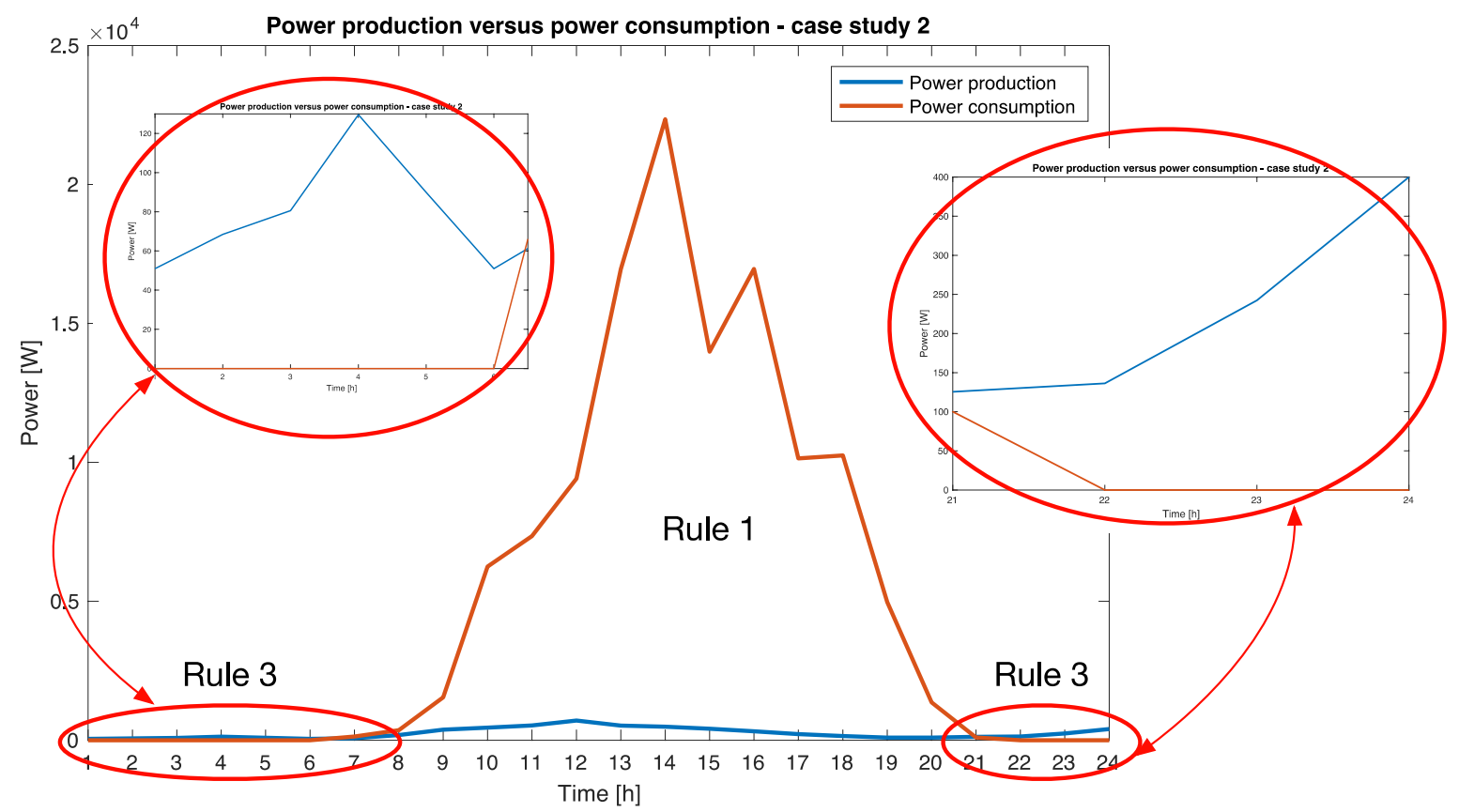

Figure 15. Load-generation curves for the day of 5 May: case study 2.

An application of the developed decision tree can be observed on Figure 15 and an hourly detail of the applied rules can be seen in Table 3. The figure shows that during the night (1 a.m. to 6 a.m.; 9 p.m. to 12 p.m.) the consumer is not active, so it does not use any electricity. Since the wind turbine had favorable weather conditions, it generated and the DSS system commands the link with the battery bank so that this outcome can be accumulated for later use. During daytime (7 a.m. to 9 p.m.) the ICSTM consumption is around $25 \mathrm{~kW}$, so it cannot be covered by the RES generation in the pilot microgrid, so the DSS rule involves the connection to the national grid.

Table 3. Application of DSS decision rules on the pilot microgrid.

\begin{tabular}{cccc}
\hline Time Interval & Applied Rule & Condition & Action \\
\hline 1 a.m.-6 a.m. & Rule 3. & $\mathrm{P}_{\mathrm{CONS}}<\mathrm{P}_{\mathrm{PV}}+\mathrm{P}_{\mathrm{EOL}}$ & Battery connection for loading \\
7 a.m.-9 p.m. & Rule 1: & $\mathrm{P}_{\mathrm{CONS}}>\mathrm{P}_{\mathrm{PV}}+\mathrm{P}_{\mathrm{EOL}}+\mathrm{P}_{\mathrm{BAT}}$ & Public Network (Grid) Connection \\
9 p.m.-12 p.m. & Rule 3. & $\mathrm{P}_{\mathrm{CONS}}<\mathrm{P}_{\mathrm{PV}}+\mathrm{P}_{\mathrm{EOL}}$ & Battery connection for loading \\
\hline
\end{tabular}

The benefits of using such a system are multiple in terms of energy consumption costs (since the load is not always connected to the grid and it operates in "island mode"), as well as $\mathrm{CO}_{2}$ emission reduction (using the renewable power sources). For a residential household, during spring to autumn months when the radiance is high, half of the consumed energy can be supplied from the microgrid, so the energy bill will decrease accordingly. However, this would not be possible without the DSS system because during peak production and lower load periods, the energy would be spilled and not saved for later in batteries, as it happens with the DSS control. 


\section{Conclusions}

We have presented the design, development, and implementation of a decision support system for a low-voltage microgrid. The model revolves around a real operational microgrid system that includes solar and wind energy generation, and energy storage batteries as well. Considering the software implementation, the approach is flexible as to accommodate different microgrid structures and patterns.

The proposed decision support system is based on a decision table with five rules that are explained in detail in respect to the implemented microgrid. Two case studies were presented: a household with lower energy consumption and an office building (the ICSTM institute) with high energy consumption during work hours. The experimental results showed the application of the proposed rules and it have demonstrated the validity of the approach in terms of energy cost reduction, as well as an efficient use of the produced renewable energy with the battery deployment.

The provided tool is relevant to several stakeholders (energy providers, consumers, etc.) which can deploy it for more reliable, safer, and economic operation of their electrical (micro-)grid.

Future work aims at implementing finer-grained rules within the decision support framework and associated software, as well as improves and account for load and weather predictions to improve the decision mechanisms for the microgrid operator. Additionally, a success metric can be computed since, for now, just a qualitative gain in terms of energy provided by the microgrid subsystems was considered (and not supplied from the national grid).

Acknowledgments: This work was mainly supported by the Romanian National Authority for Scientific Research, CNDI-UEFISCDI, project code PN-II-PT-PCCA-2011-3.2-1616, “Intelligent Decision Support and Control System for Low Voltage Grids with Distributed Power Generation from Renewable Energy Sources" (INDESEN), Contract nr. $42 / 2012$.

Author Contributions: Iulia Stamatescu and Nicoleta Arghira wrote major paragraphs of the paper and integrate the contributions written by the other authors. Ioana Făgărăşan provided algorithms and principles used for fault detection and diagnosis modules, and offered guidance and supervised the development of these modules. All the paragraphs regarding these aspects are written by this author. Sergiu-Stelian Iliescu conceived the idea of research and provided guidance. Grigore Stamatescu and Vasile Calofir performed the analysis for the relevant study case and provided the results used for demonstration in this article. All authors have contributed significantly to this work.

Conflicts of Interest: The authors declare no conflict of interest.

\section{References}

1. Tristan Glenwright, Introduction to Microgrids, U.S. Department of Energy, Office of Electricity Delivery and Energy Reliaility. 2012. Available online: www.oe.energy.gov (accessed on 6 October 2016).

2. Elena Dragomir, O.; Dragomir, F.; Stefan, V.; Minca, E. Adaptive Neuro-Fuzzy Inference Systems as a Strategy for Predicting and Controling the Energy Produced from Renewable Sources. Energies 2015, 8, 13047-13061. [CrossRef]

3. Rasheed, M.B.; Javaid, N.; Awais, M.; Khan, Z.A.; Qasim, U.; Alrajeh, N.; Iqbal, Z.; Javaid, Q. Real Time Information Based Energy Management Using Customer Preferences and Dynamic Pricing in Smart Homes. Energies 2016, 9, 542. [CrossRef]

4. Liang, H.; Zhuang, W. Stochastic Modeling and Optimization in a Microgrid: A Survey. Energies 2014, 7 , 2027-2050. [CrossRef]

5. Beykverdi, M.; Jalilvand, A.; Ehsan, M. Cooperative Energy Management of Hybrid DC Renewable Grid Using Decentralized Control Strategies. Energies 2016, 9, 859. [CrossRef]

6. Arghira, N.; Hawarah, L.; Ploix, S.; Jacomino, M. Prediction of appliances energy use in smart homes. Energy 2012, 48, 128-134. [CrossRef]

7. Europeean Stategie for 2020. Available online: http://ec.europa.eu/europe2020/europe-2020-in-a-nutshell/ priorities/index_ro.htm (accessed on 6 October 2016).

8. Cha, H.-J.; Won, D.-J.; Kim, S.-H.; Chung, I.-Y.; Han, B.-M. Multi-Agent System-Based Microgrid Operation Strategy for Demand Response. Energies 2015, 8, 14272-14286. [CrossRef] 
9. Oh, S.-J.; Yoo, C.-H.; Chung, I.-Y.; Won, D.-J. Hardware-in-the-Loop Simulation of Distributed Intelligent Energy Management System for Microgrids. Energies 2013, 6, 3263-3283. [CrossRef]

10. Kuo, M.-T.; Lu, S.-D. Design and Implementation of Real-Time Intelligent Control and Structure Based on Multi-Agent Systems in Microgrids. Energies 2013, 6, 6045-6059. [CrossRef]

11. Giordano, V.; Meletiou, A.; Covrig, C.F.; Mengolini, A.; Ardelean, M.; Fulli, G.; Jimenez, M.S.; Filiou, C. Smart Grid projects in Europe: Lessons learned and current developments. Jt. Res. Cent. Inst. Energy Transp. 2013. [CrossRef]

12. Package of Implementation Measures for the EU's Objectives on Climate Change and Renewable Energy for 2020, Directive of the European Parliament and of the Council on the Promotion of Use of Renewable Energy Sources, \{COM (2008) 19\}. Available online: http://ec.europa.eu/energy/climate_actions/doc/2008_res_ia_ en.pdf (accessed on 6 October 2016).

13. Jain, N.; Alleyn, A.G. A framework for the optimization of integrated energy systems. Appl. Therm. Eng. 2012, 48, 495-505. [CrossRef]

14. Robescu, L.D.; Lazaroiu, G.C.; Dumbrava, V.; Manea, E.; Presura, A. Optimizing electricity costs of wastewater treatment plant in presence of RES and power market. In Proceedings of the 9th International Symposium on Advanced Topics in Electrical Engineering (ATEE), Bucharest, Romania, 7-9 May 2015; pp. 808-811.

15. Jain, A.; Duin, R.P.W.; Mao, J. Statistical pattern recognition: A review. IEEE Trans. Pattern Anal. Mach. Intell. 2000, 22, 4-37. [CrossRef]

16. Mayne, D.; Falugi, P.J. Generalized Stabilizing Conditions for Model Predictive Control. J. Optim. Theory Appl. 2016, 169, 719. [CrossRef]

17. Integration of Renewable Energy Sources and Distributed Generation into the European Electricity Grid Cluster. Available online: http:/ / www.ired-cluster.org/ (accessed on 6 October 2016).

18. Filip, F.G. Decision Support Systems (Sisteme Support Pentru Decizii); Technical Publishers: Bucharest, Roamania, 2004.

19. Torrent-Fontbona, F.; Lopez, B. Decision support for grid-connected renewable energy generators planning. Energy 2016, 115, 577-590. [CrossRef]

20. Girones, V.C.; Moret, S.; Marechal, F.; Favrat, D. Strategic energy planning for large-scale energy systems: A modelling framework to aid decision-making. Energy 2015, 90, 173-186. [CrossRef]

21. Born, F.J.; Clarke, J.A.; Johnstone, C.M. Development and demonstration of a renewable energy based energy demand/supply decision support tool for the building design profession. In Proceedings of the 7th IBPSA Conference, Rio de Janeiro, Brazil, 13-15 August 2001; pp. 1-8.

22. Bartolozzi, M.; Bellini, P.; Nesi, P.; Pantaleo, G.; Santi, L. A Smart Decision Support System for Smart City. In Proceedings of the 2015 IEEE International Conference on Smart City, Guadalajara, Mexico, 25-28 October 2015; pp. 117-122.

23. Pupaza, D. Industrial Informatics System Analysis (Analiza de Sistem in Informatica Industriala); Agir Publisher: Bucharest, Romania, 2006.

24. Azim, R.; Li, F. A Decision Tree Based Approach for Controlled Islanding of Microgrids. In Proceedings of the 2016 IEEE/PES Transmission and Distribution Conference and Exposition, Dallas, TX, USA, 3-5 May 2016; pp. 1-5.

25. ICSTM Multidisciplinary Scientific and Technologic Research Institute (ICSTM) of "Valahia" University of Targoviste (UVT) Homepage. Available online: http:/ /916.icstm.ro (accessed on 6 October 2016).

26. PWX500, PhotoWatt International. Available online: http://pdf.archiexpo.com/pdf/photowatttechnologies/photowatt-pwx500--12v/62614--84848.html (accessed on 6 October 2016).

27. PV ST220, Sunshine Solar Technology. Available online: http://www.sunshinesolar.com.cn/product_show. asp?id=904 (accessed on 6 October 2016).

28. Dragomir, O.E.; Dragomir, F.; Radulescu, M. Matlab Application of Kohonen Self-Organising Map to Classify Consumers' Load Profiles. Procedia Comput. Sci. 2014, 31, 474-479. [CrossRef]

29. Fagarasan, I.; Ploix, S.; Gentil, S. Causal fault detection and isolation based on a set-membership approach. J. Autom. 2004, 40, 2099-2110.

30. Dragomir, F.; Dragomir, O.E. Forecasting of photovoltaic power generation by RBF neural networks. Adv. Mater. Res. 2014, 918, 200-205. [CrossRef] 
31. Stamatescu, I.; Stamatescu, G.; Arghira, N.; Făgărăsan, I.; Iliescu, S.S. Fuzzy decision support system for solar tracking optimization. In Proceedings of the 2014 International Conference on Development and Application Systems (DAS), Suceava, Romania, 15-17 May 2014.

32. Bonczek, R.H.; Holsapple, C.W.; Whinston, A.B. Future directions in developing decision support systems. Decis. Sci. 1980, 11, 616-631. [CrossRef]

33. Bonczek, R.H.; Holsapple, C.W.; Whinston, A.B. Foundation of Decision Support Systems; Academic Press: New York, NY, USA, 1981.

34. Burstein, F.; Holsapple, C. Handbook on Decision Support Systems 1. In International Handbooks on Information Systems; Springer: Berlin/Heidelberg, Germany, 2008.

35. Online Database for Wind Production. Available online: http://www.energinet.dk/en/el/engrosmarked/ udtraek-af-markedsdata/Sider/default.aspx (accessed on 6 October 2016).

(C) 2017 by the authors; licensee MDPI, Basel, Switzerland. This article is an open access article distributed under the terms and conditions of the Creative Commons Attribution (CC-BY) license (http://creativecommons.org/licenses/by/4.0/). 